
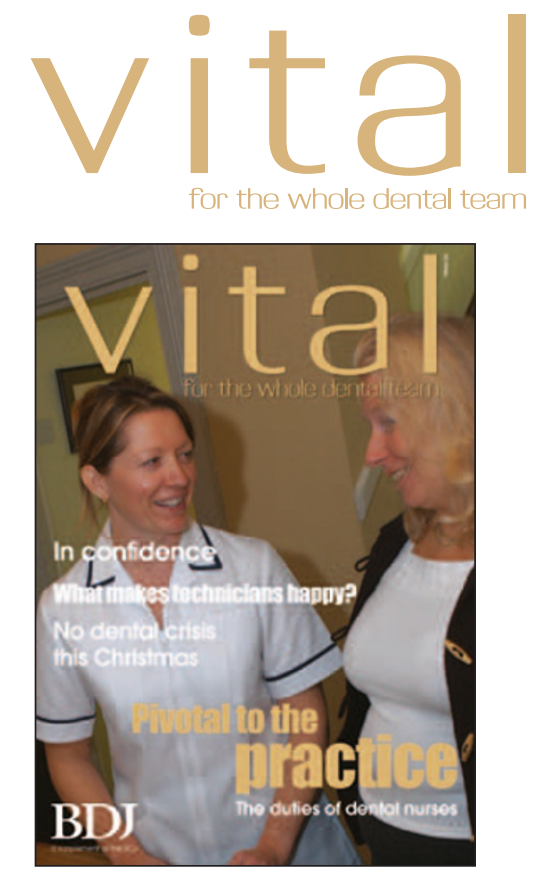

VITAL for the whole dental team

Editor: Kate Craig

Deputy Editor: Naomi Scott

Design Editor: Melissa McClean

Staff writers: Arveen Bajaj, Kate Maynard

Consultant Editor: Fiona Stuart-Wilson

\section{Publishing Manager:}

Kim Black-Totham

Advertising Sales Director:

Joe Aspis

Display Advertising Sales:

Matt Wooding

Classified Sales:

Alison Tant

Advertising enquiries:

+44 (0)20 78434785

Production Controller: Sarah Hilton

Vital Editorial Board: Julia Brewin

Michelle Brindley, Larry Browne, Claire

Crocker, Ruth Glover, Fiona Stuart-Wilson,

Gordon Watkins, Margaret Wilson

British Dental Journal

The Macmillan Building

4-6 Crinan Street

London N1 9XW

Tel: + $44(0) 2078433678$

Fax: + $44(0) 2078434725$

C) British Dental Journal 2004. All rights reserved. No part of this publication may be reproduced, stored in a retrieval system or transmitted in any form or by any means, electronic, mechanical, photocopying, recording or otherwise, without the prior permission of the British Dental Journal.

The opinions expressed in this publication are those of the authors and not necessarily those of the British Dental Association or the editor. Appearance of an advertisement does not indicate BDA approval of the product or service.

\section{Supported MRICLEV
by Oral Healthcare in Action}

Turn to page 50 to subscribe to receive future issues

\section{Happy Anniversary}

This issue marks the first anniversary for Vital.

From our launch at last year's Dental Showcase exhibition, the magazine has been welcomed by dental teams throughout the UK.

It's been a fantastic year for Vital; as well as keeping you up-to-date on the latest registration information and dental news, we've met dental nurses in New Zealand and Canada, sailed to Africa with Mercy Ships International and gained an insight into life in the armed forces.

Even better, it's been a two-way communication. Through our Perspectives and Letters sections you've shared your opinions with one another, and with us. From your response it has been obvious that a publication aimed at the whole team was well overdue. Please continue sending your feedback so we can ensure Vital remains vital reading for you and your colleagues.

This issue we travel to India, take a look at practice ethics and focus on the festive season. Dental hygienist Liz Deuchars shares her experiences as Crisis Dental Service Coordinator on page 24. Crisis works year round to help vulnerable and marginalised people live through the crisis of homelessness and the charity is best known for its Christmas shelters. If you would like to volunteer your own services this Christmas, see page 6 for details.

Dental nurse Rosey Prior took things a step further when she travelled to India with her dentist in 2002 (page 26). Rosey spent four weeks in Chikratoot in North India teaching the local dental nurses basic skills and communication techniques. Although incredibly rewarding in itself, the experience also made Rosey appreciate how good things were at home.

But dental nurses don't need to leave the UK to make a difference. Nursing is the focus of this issue's 'day in the life' feature, and Christopher Sell discovers what a pivotal role dental nurses play when he follows nurses in two contrasting practices on page 31 .

As 2004 draws to a close, upcoming GDC registration remains the hottest topic for many PCDs. Increased individual responsibility towards ensuring ethical practice is something registrants should be aware of.

With this in mind, this issue's advice section focuses on ethics (page 36). Ensuring ethical practice is not only the responsibility of the dentist, but a vital part of the role of all team members. A model practice confidentiality policy can be found on page 40 .

Long-awaited registration and the upcoming NHS dentistry reforms are at the forefront of our thoughts as 2005 fast approaches. May you all have a happy and healthy festive season, returning refreshed for the challenges, and opportunities, 2005 will bring.

Merry Christmas from the whole Vital team.
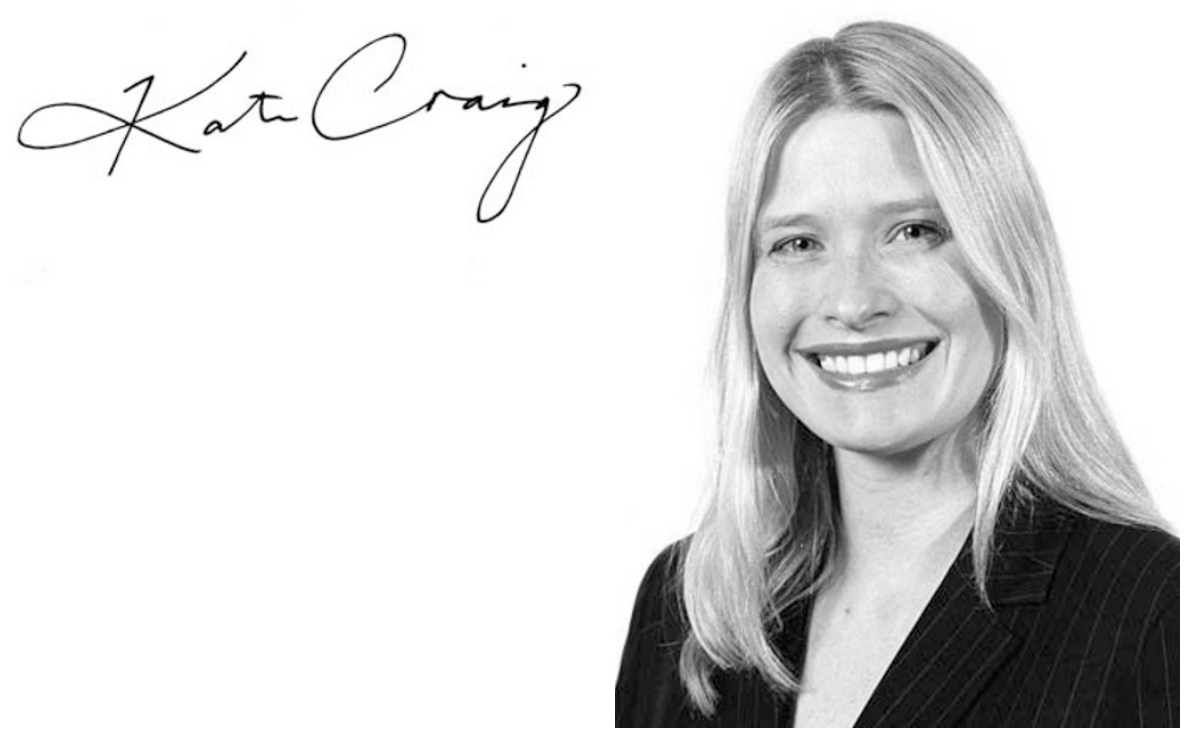

winter $04 \mathbf{0 3}$

vital 